\title{
Cracking Process Related to Hydrogen Behavior in a Duplex Stainless Steel
}

\author{
Afshin YOUSEFI, ${ }^{1)}$ Goroh ITOH, ${ }^{1 / *}$ Zoha GHORANII) and Shigeru KURAMOTO ${ }^{1)}$ \\ 1) Major in Mechanical Systems Engineering, School of Science and Engineering, Graduate School of Ibaraki University, \\ Hitachi, Ibaraki, 316-8511 Japan. \\ 2) Graduate Student, Major in Complex Systems Science, Graduate School of Science and Engineering, Ibaraki University, \\ Hitachi, Ibaraki, 316-8511 Japan.
}

(Received on March 26, 2019; accepted on June 13, 2019)

\begin{abstract}
Cracking process in hydrogen embrittlement (HE) of a duplex stainless steel (DSS) was investigated. Annealed DSS (SUS329J4L) specimens with phase volume fraction of about 50:50 were electrolytically hydrogen-charged and deformed in ambient atmosphere at a strain rate of $1.38 \times 10^{-4} \mathrm{~s}^{-1}$. Microcracks were observed mostly to start and pass in the ferrite phase in the course of the deformation. In contrast, austenite phase acted as an obstacle against crack propagation. Delamination was also observed in accord with the authors' previous study, and the delamination crack also initiated and propagated in ferrite phase. Hydrogen microprint technique (HMPT) revealed that hydrogen atoms migrate mainly in ferrite phase over the distance of the sample thickness. Considering this long diffusion distance of hydrogen, dimpled area observed around the center of the fracture surface was attributable to the sharp increase in the strain rate because of the localized deformation arising from the major crack propagation. HMPT also revealed a marked effect of elastic stress on the acceleration of hydrogen diffusion. Thermal desorption spectroscopy (TDS) confirmed that some of the hydrogen diffuses out during keeping the specimen in the ambient atmosphere, which was accelerated by deformation during keeping presumably by the mechanism of hydrogen transport with gliding dislocations. Furthermore, TDS results demonstrated that the majority of the hydrogen migrated and was trapped by a site with lower binding energy during the deformation.
\end{abstract}

KEY WORDS: hydrogen embrittlement; duplex stainless steel; fractography; crack initiation; crack propagation; hydrogen microprint technique; thermal desorption spectroscopy.

\section{Introduction}

Duplex stainless steels (DSSs) represent a combination of good mechanical properties and high resistance to stress corrosion cracking. These characteristics are achieved through a dual phase microstructure containing nominally 50 to $50 \%$ volume fractions of austenite and ferrite. ${ }^{1,2)}$ DSSs are very considerable materials for pressure vessels, underground and underwater pipelines, and are applied in industries especially oil, gas, petroleum and petrochemical fields. ${ }^{3-7)}$ On the other hand, hydrogen has a critical effect on service life of DSSs especially in combination with mechanical load, reducing their ductility and resistance to fracture, ${ }^{8-12)}$ known as hydrogen embrittlement (HE). ${ }^{13-17)}$ Consequently, much effort has been devoted to characterizing and determining the factors affecting HE. ${ }^{18-26)}$ Although the atomistic process of HE is still being discussed and not fully understood yet, it has been established that hydrogen atoms enter the metals from environment via the absorption and diffusion, and that they influence on the crack initiation and propagation. ${ }^{27,28)}$ The hydrogen atoms in steels have been roughly

* Corresponding author: E-mail: goroh.itoh.ibaraki@vc.ibaraki.ac.jp DOI: https://doi.org/10.2355/isijinternational.ISIJINT-2019-159 divided into two categories: one is non-diffusive hydrogen atoms strongly trapped by stable trapping sites such as precipitates and inclusions, and the other is diffusive hydrogen atoms that are in the interstitial site of the matrix or lightly trapped by less stable sites such as dislocations and grain boundaries. $^{26)}$

In the previous study, ${ }^{29)}$ the authors investigated tensile properties of an electrolytically hydrogen-charged DSS affected by the strain rates ranging from $1.38 \times 10^{-7} \mathrm{~s}^{-1}$ to $1.38 \times 10^{-3} \mathrm{~s}^{-1}$, and found that the susceptibility to $\mathrm{HE}$ becomes largest at a strain rate of $1.38 \times 10^{-4} \mathrm{~s}^{-1}$ in this charging and testing method. Furthermore, delamination type of fracture was seen in the specimen with high susceptibility to the HE.

In the research on the HE in DSSs, the major interests have been initiation and propagation site of the crack, trapping site and diffusion path of hydrogen. Therefore, we need to study further on our previous results in terms of the above-mentioned three points: crack initiation/propagation site, trapping site and diffusion path. However, even after summarizing the previous papers, there has been no certain conclusion in all the three points, which will be mentioned in detail later in this paper.

Seeing the status on the studies on HE in DSS as men- 
tioned above, we have made an attempt to understand initiation site and propagation path of the main crack as well as delamination crack, by close observation on the fracture surface and the area close to the fracture point. On the trapping site and the diffusion path of hydrogen, we have performed hydrogen microprint technique (HMPT) ${ }^{26)}$ on wide area to get quantitative information. In addition, thermal desorption spectroscopy (TDS $)^{30)}$ were conducted to correlate the cracking process to the hydrogen behavior by acquiring information on the distribution and concentration of hydrogen before and after plastic deformation.

\section{Material and Experimental Procedure}

\subsection{Material and Hydrogen Charging}

The material used in this study is the same DSS (SUS329J4L) sheet with $1 \mathrm{~mm}$ thickness as in the previous study $^{29)}$ annealed at $1055^{\circ} \mathrm{C}$ for $18 \mathrm{~min}$ and then watercooled, containing $51 \mathrm{Vol} \%$ ferrite and $49 \mathrm{Vol} \%$ austenite phases. Its chemical composition is listed in Table 1. Slow strain rate technique (SSRT) tensile test pieces were cut from the sheet in the longitudinal direction by electric discharge machining (EDM), with the gage length of $12 \mathrm{~mm}$, and width of $5 \mathrm{~mm}$. The test pieces of the same shape and dimension were used also in HMPT experiments. Then the test pieces were ground with waterproof abrasive paper up to 2000 grit, mirror finished by buffing with diamond paste up to $0.25 \mu \mathrm{m}$, and finally etched with aqua regia. The reduction in thickness in the above operation was about 200 $\mu \mathrm{m}$ (final thickness: $0.8 \mathrm{~mm}$ ). The surfaces were rinsed with distilled water, cleaned ultrasonically in acetone, and dried quickly by warm air. The charging was performed at room temperature (RT) for $24 \mathrm{~h}$ with platinum anode in a sulfuric acid aqueous solution with $\mathrm{pH}=2.5$ containing 0.1 mass $\%$ of $\mathrm{NH}_{4} \mathrm{SCN}$ as a hydrogen recombination inhibitor with a current density of $100 \mathrm{~A} \cdot \mathrm{m}^{-2}$ and voltage of $10 \mathrm{~V}$.

\subsection{Tensile Test}

Figure 1 shows elongation to failure of the DSS at different strain rates ranging from $1.38 \times 10^{-7} \mathrm{~s}^{-1}$ to $1.38 \times 10^{-3} \mathrm{~s}^{-1}$, which has been already reported in the previous paper. ${ }^{29)}$ From this figure, the extent of HE took a maximum at a strain rate of $1.38 \times 10^{-4} \mathrm{~s}^{-1}$ and this strain rate has been adopted in this study. In this study as well, immediately after hydrogen charging of etched specimen, tensile test was carried out at the strain rate of $1.38 \times 10^{-4} \mathrm{~s}^{-1}$ by using a Toshin Kogyo 2LP-2R testing machine, but without simultaneous charging, i.e., charging was not made during the tests. At the tensile strains of 8, 12, 16 and 20\% before fracture (total elongation to failure was $25 \%$ ), specimen was removed from the testing device and its surface was observed by a scanning electron microscope (SEM; Hitachi, S-3400) equipped with an energy dispersive X-ray spectroscopy (EDX), to investigate the crack initiation site and crack

Table 1. Chemical composition of the SUS329J4L specimen in $\operatorname{mass} \%$.

\begin{tabular}{cccccccc}
\hline $\mathrm{C}$ & $\mathrm{Si}$ & $\mathrm{Mn}$ & $\mathrm{Cr}$ & $\mathrm{Mo}$ & $\mathrm{N}$ & $\mathrm{Ni}$ & $\mathrm{Fe}$ \\
\hline 0.013 & 0.53 & 0.83 & 25.04 & 3.07 & 0.14 & 7.01 & Bal. \\
\hline
\end{tabular}

propagation path.

\subsection{HMPT}

The HMPT is a technique for visualizing the hydrogen atoms released at the surface of specimens. The basic principle of HMPT contains coating the surface of the previously hydrogen-charged specimen with a high-resolution nuclear emulsion. When hydrogen atoms are emitted from the specimen, they react with silver bromide in a gelatin film, leaving silver particles on the specimen surface. After fixing, i.e., removing the unreacted silver bromide, one can observe the emission points of hydrogen atoms as silver particles. For HMPT in this research, hydrogen was charged on one side of the specimen under the same condition as mentioned above, while the other (hydrogen exit) side was covered with emulsion (Ilford L4 diluted by 4 times) containing $\mathrm{AgBr}$ in a darkroom with wire loop method. After applying the nuclear emulsion, the surface layer of the specimen was dried carefully by mild flow of warm air. After the gage portion of the specimens was covered with aluminium foil, the specimens were tensile-loaded up to 30, 60 and $90 \%$ of $0.2 \%$ proof stress $(650 \mathrm{MPa})$. The time taken to finish the loading up to the $90 \%$ of proof stress was 20 minutes. Then, the specimens were unloaded right after the stress reached the designated value, and subsequently kept in the darkroom (total time from the covering to the next step (fixing) was 24 h). Finally, the specimens were fixed with Super Fuji Fix solution for $15 \mathrm{~min}$, washed with running water for $15 \mathrm{~min}$, dried and observed with the EDX-equipped SEM.

\subsection{TDS}

The TDS was performed with an EMD-WA1000S/W machine produced by ESCO Ltd., Japan. A specimen cut from the sheet with dimension of $5 \mathrm{~mm} \times 5 \mathrm{~mm}$ set in the pre-evacuation chamber with total pressure less than $1 \times 10^{-4} \mathrm{~Pa}$ was transferred onto the quartz stage in the main chamber by a carrying device. After the pressure in the main chamber reached below $3 \times 10^{-7} \mathrm{~Pa}$, the specimen was heated from $\mathrm{RT}$ to $350^{\circ} \mathrm{C}$ at a constant heating rate of $100^{\circ} \mathrm{C} / \mathrm{h}$ and cooled in the chamber, and re-heated under the same conditions after the temperature of the specimen reached to RT in order to measure the background pressure depending on the temperature. ${ }^{30)}$ During the test, $\mathrm{H}_{2}{ }^{+}$ion current was electrically measured by the quadrupole mass

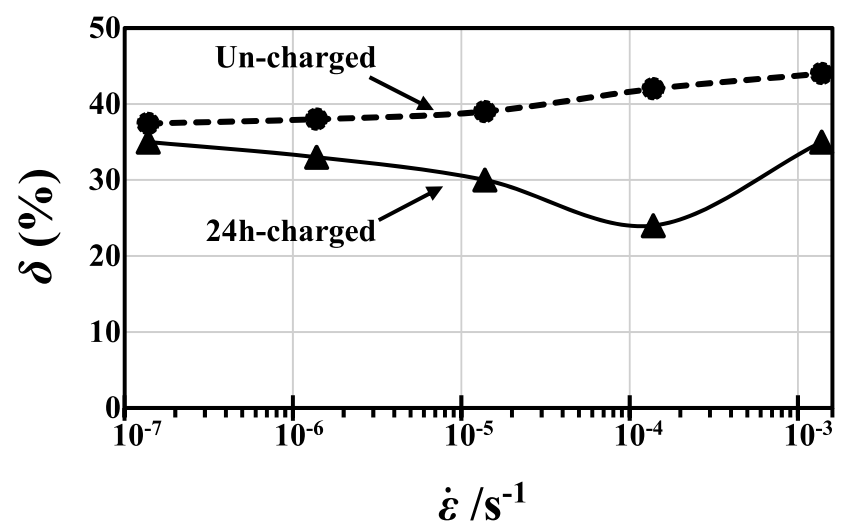

Fig. 1. Elongation to failure, $\delta$, as a function of strain rate, $\dot{\varepsilon}$, of the specimens uncharged and electrolytically hydrogencharged for $24 \mathrm{~h}$. 
spectrometer. The heating was made indirectly through the stage baked by infrared radiation. In this research, three specimens were examined by TDS, i) right after hydrogen charging, ii) right after fracture, and iii) after keeping the charged specimens at ambient environment for the same duration as was taken up to the fracture. The specimen ii) was cut from the area as close as possible to the fracture point (with tensile strain of about $25 \%$ ) around $1 \mathrm{~mm}$ from the fracture surface.

\section{Experimental Results}

\subsection{Tensile Test and Fractography}

Example of the microstructure of the etched specimen is shown in Fig. 2 by using secondary electron imaging mode of the EDX-equipped SEM. We can recognize two phases: light phase looking like matrix and dark phase looking like island-shaped precipitate phase. The concentration of $\mathrm{Cr}$ and $\mathrm{Ni}$ elements was quantitatively measured at a point around the center of the two phases by assuming the specimen as a purely ternary alloy, to confirm the relationship between the phase and contrast in the etched specimen in the SEM image. The result of the quantitative analysis is shown in Table 2. From this result, it is concluded that the light area

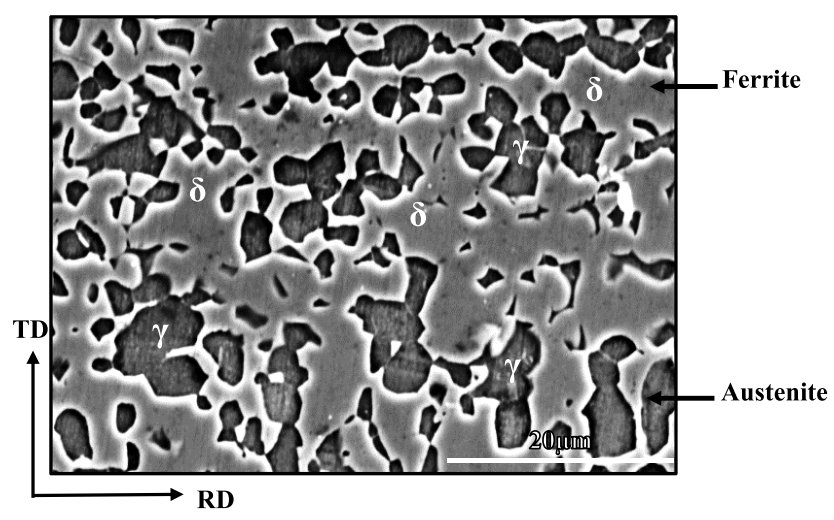

Fig. 2. Microstructure (secondary electron image) of the specimen. $\delta$ : ferrite, $\gamma$ : austenite. with larger amount of $\mathrm{Cr}$ is ferrite, while the dark area with larger amount of $\mathrm{Ni}$ is austenite. The two phases are labeled as $\delta$ and $\gamma$ in Fig. 2, respectively, for easy understanding.

Figure 3 shows the stress-strain curves of charged and uncharged specimens. Elongation is decreased by charging, but still the charged specimen has elongation of $25 \%$. Figures 4(a), 4(b) and 4(c) show the fracture surface of the uncharged specimen. Significant necking near the middle portion of gage width area can be seen in Fig. 4(a) at low magnification, and dimples together with shear surface is visible in Figs. 4(b) and 4(c) at high magnification. Both of these features represent ductile fracture behavior. The appearances of the test piece near the fracture point and

Table 2. Result of quantitative analysis in $\mathrm{Cr}$ and $\mathrm{Ni}$ in mass $\%$ in the two phases indicated in Fig. 2.

\begin{tabular}{ccc}
\hline Element & Austenite & Ferrite \\
\hline $\mathrm{Cr}$ & 24.3 & 28.4 \\
$\mathrm{Ni}$ & 12.0 & 8.5 \\
$\mathrm{Fe}$ & 63.7 & 63.1 \\
Total & 100.0 & 100.0 \\
\hline
\end{tabular}

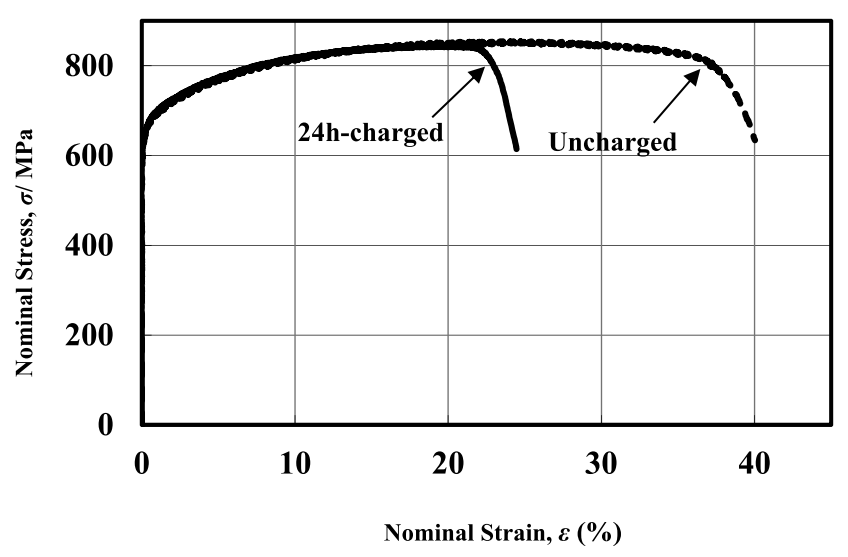

Fig. 3. Stress-strain curves for specimens uncharged and charged for $24 \mathrm{~h}$ tensile-tested at a strain rate of $1.38 \times 10^{-4} \mathrm{~s}^{-1}$.

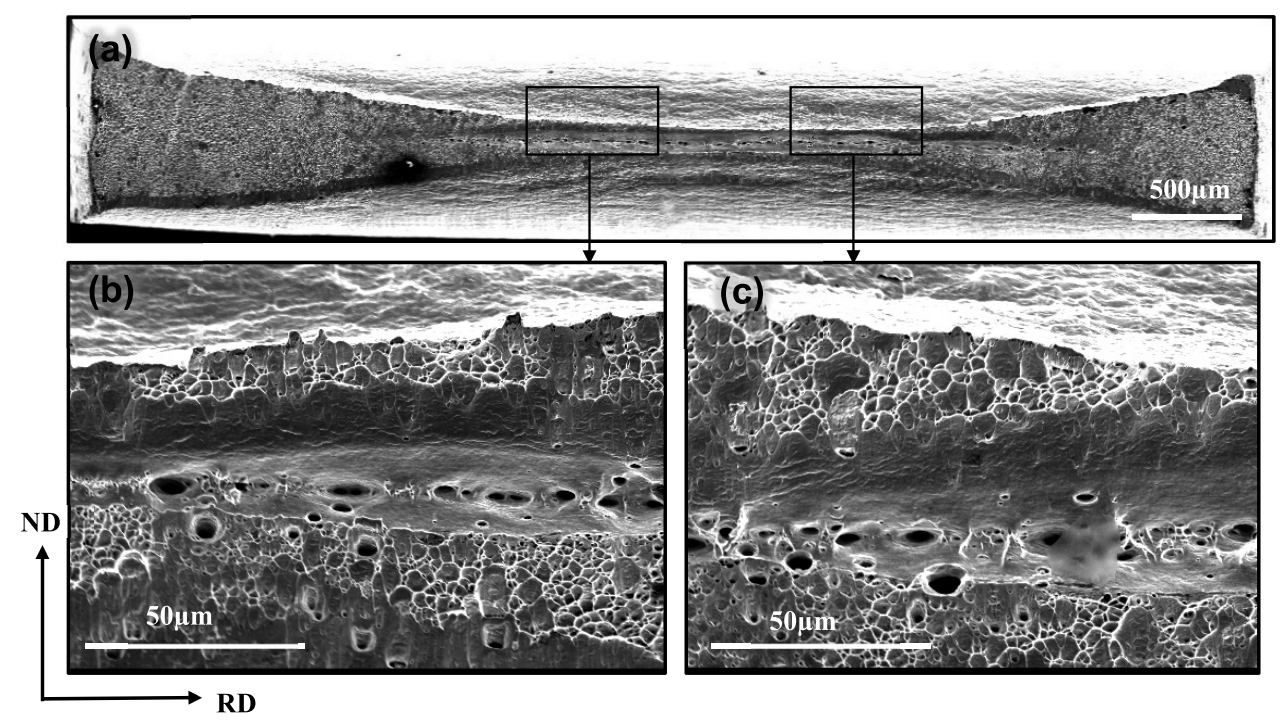

Fig. 4. SEM fractography of the uncharged fracture specimen of DSS after SSRT at $1.38 \times 10^{-4} \mathrm{~s}^{-1}$. (a) overall view, (b) and (c) high magnification for the area indicated in Fig. 4(a). 
fracture surface of the charged specimen are shown in Figs. 5(a) to 5(d). The charged specimen shows step cracks and delamination (cracking that occurs parallel to the tensile direction and to the specimen surface), which were thought as the influence of hydrogen. On the other hand, numerous dimples can be seen in some areas in the fracture surface,
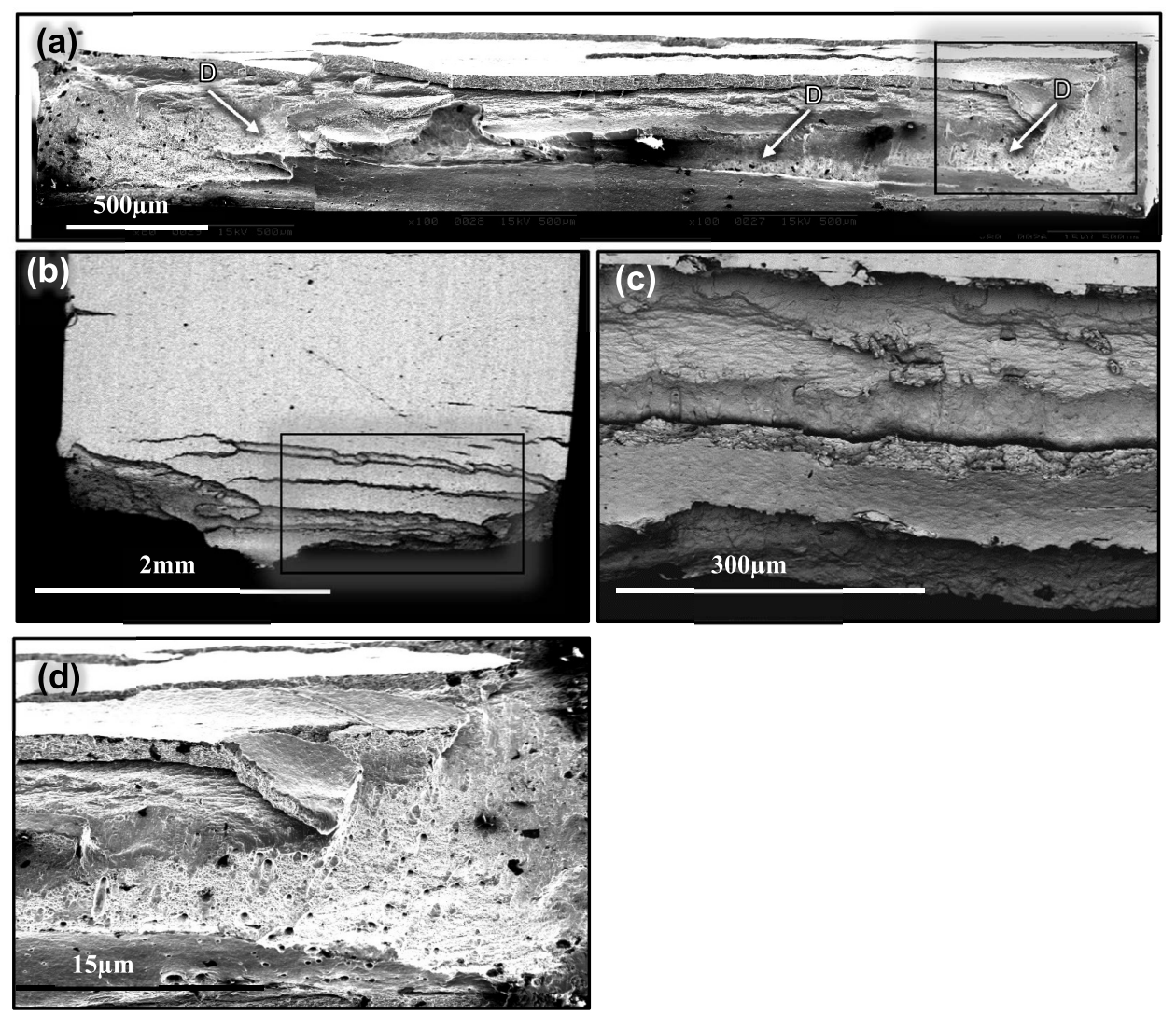

Fig. 5. SEM images showing fracture surface and appearance near the fracture point of the charged specimen. (a) fracture surface at low magnification, (b) appearance near the fracture point, (c) close-up image of the boxed portion of (b) from a different angle $\left(30^{\circ}\right)$, (d) close-up image of the dimpled area (indicated by a box) in (a).
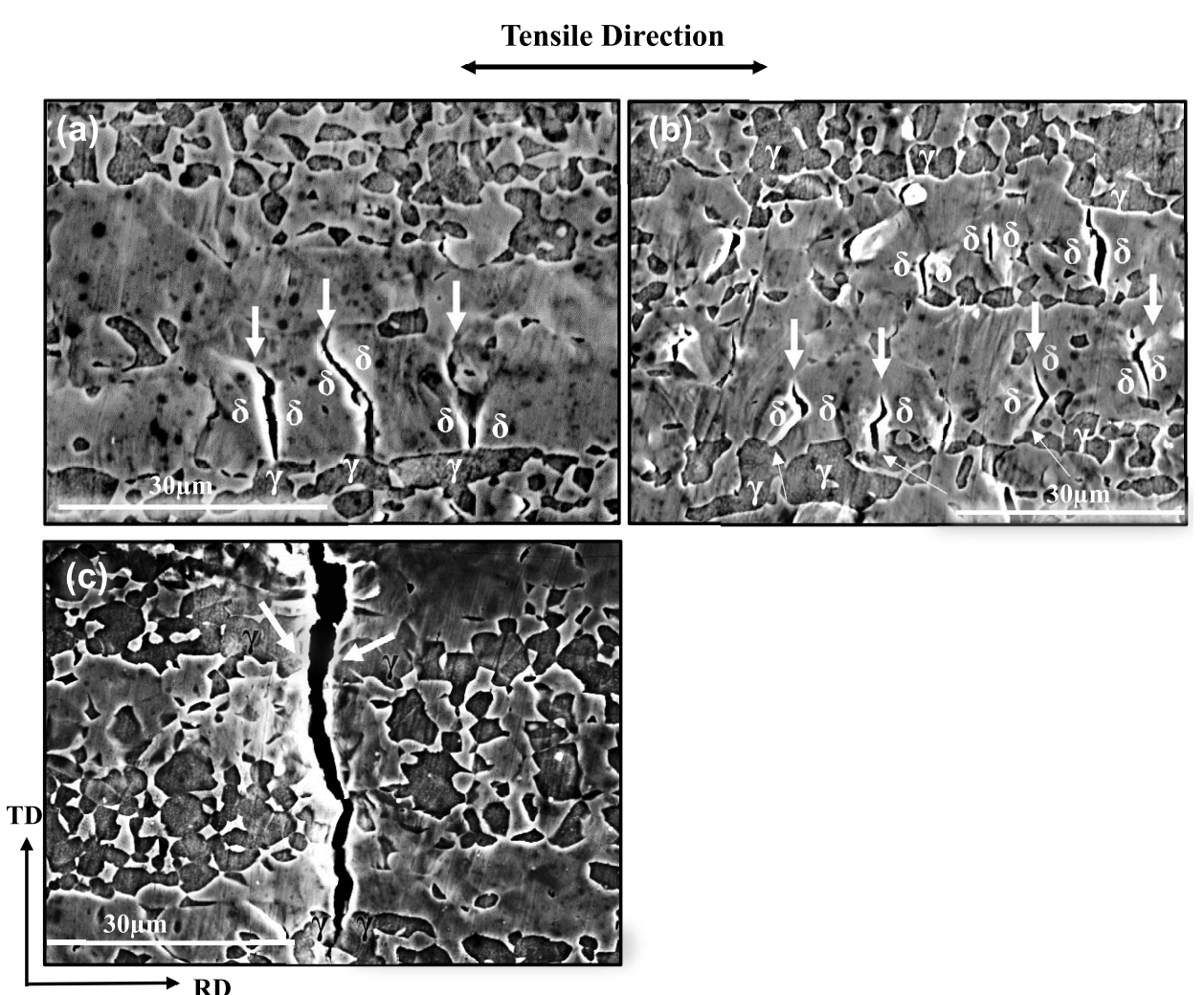

Fig. 6. SEM images of the surface of the test piece charged and deformed $12 \%$ (a), $16 \%$ (b) and $20 \%$ (c). 
which is located in the area with some distance from the original surface and indicated by arrows " $D$ ". These features have already been reported in the previous paper, ${ }^{29)}$ but they will be further investigated more in detail in the present paper. For the charged specimen, deformation was interrupted at nominal strains of 8, 12, 16 and 20\% and the surface was observed with the SEM. When the deformation was below 12\%, no crack was visible. Figures 6(a), 6(b) and 6(c) show SEM images of the surface of the test piece charged and deformed 12\%,16\% and 20\%, respectively. For the specimen deformed $12 \%$, a few microcracks are seen initiated inside ferrite phase grain. When the deformation proceeds up to $16 \%$, number of the microcracks is increased. The cracks are indicated by thick arrows in Fig. 6(b) and are found exclusively within ferrite grains (light grains in Fig. 6(b)), and austenite grains seem to protect the crack propagation as shown by thin arrows. When the deformation amount reaches $20 \%$, one of the microcracks propagates to a main crack (Fig. 6(c)), which occasionally goes through an austenite grain, as indicated by a thick arrow. It has been reported that the diffusivity and solubility of hydrogen are larger and smaller, respectively, inside ferrite grains than austenite. ${ }^{32)}$ The cracking behavior observed in this research is presumed to be majorly due to the higher diffusivity in ferrite grain. The occurrence of the dimpled area might be caused either by the smaller hydrogen concentration in the center of the test piece or by strain rate increase that is brought about by the localized deformation once one of the microcracks grows as the major crack. As shown in Fig. 1, higher strain rate alleviates the HE. The origin of the step cracks is deduced to be correlated with the ductile deformation both in tensile direction (rolling direction: RD) and ND (normal direction) of the core portion of the test piece. Pre-existing surface cracks should have been separated in the two directions, forming step cracks.

Figures 7(a) and 7(b) are SEM micrographs of the cross section perpendicular to TD (transverse direction) of the test pieces after fracture, both showing delamination cracking. Delamination is found in ferrite grains elongating along RD, as indicated by arrows in Figs. 7(a) and 7(b). Thus, it is concluded that the crack initiation site and the major crack path are ferrite grains. The tensile stress in ND that causes the delamination arises from necking and is much smaller than that in the RD, macroscopic tensile direction. The fact that delamination has taken place in spite of the small tensile stress implies that this longer crack path (longer ferrite grain area) is effective in the HE in DSS.

\subsection{HMPT}

To observe hydrogen distribution and diffusion paths, HMPT has been carried out on the side opposite to that electrolytically hydrogen-charged. Figures 8(a) to $8(\mathrm{c})$ show HMPT/SEM images of the test pieces 24 h-charged, covered with photographic emulsion, tensile-loaded up to three level of elastic stress, unloaded and then kept at RT for $24 \mathrm{~h}$. The small white spots observed are fine silver grains, confirmed by EDX. It is clearly noticed that the number of silver grains is increased as the elastic stress increases. The HMPT results show that the diffusion is sufficient for the hydrogen atoms to migrate from the charged side to the other. Therefore, the dimpled area is not considered due to

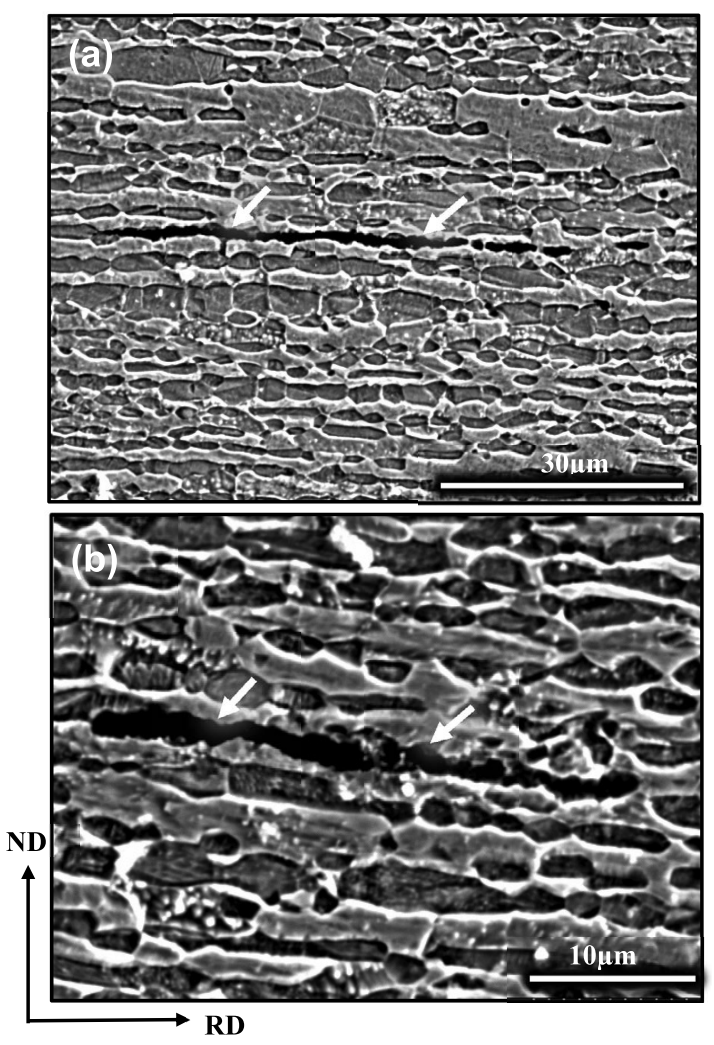

Fig. 7. SEM images of a delamination (indicated by arrows) initiation site after fracture at low (a) and high (b) magnifications.

the smaller concentration of hydrogen in the center than near the surface. The silver grains were classified according to the location in the microstructure into those on ferrite and austenite grains, and on the phase boundaries. The area percentage of silver grains in the observed area is illustrated in Fig. 9 with the result of the classification. It is quantitatively confirmed that the total fraction of silver grains is increased as the stress increases, which should be the effect of elastic stress on hydrogen diffusion. ${ }^{33)}$ To understand the result of classification, relative area of silver grains for each category is shown in Fig. 10. It is found that the sites where silver grains are noticed are mostly ferrite phase, next phase boundary (except at the stress of $60 \%$ of the proof stress) and least austenite phase. This feature should have been affected mainly by the diffusivity of hydrogen, diffusion path and trapping sites. As described earlier, hydrogen diffusivity has been reported far larger in ferrite than in austenite. ${ }^{32)}$ However, no sufficient information is available on the diffusivity and binding energy for the phase boundary. Also, no significant trend can be seen in the relative area fraction of silver grains for each category with the increase in the stress level. It is simply clear that the silver grains of all the categories increase with increasing the stress as shown in the fraction values of each category indicated in Fig. 9. Hence, we cannot clarify effect of the elastic stress on the difference in the diffusivity of hydrogen, diffusion path and trapping sites, particularly between the interior of ferrite phase and phase boundary. Further study is needed. In the photos shown in Fig. 8, since grain boundaries inside the ferrite or austenite phase is not visualized, we did not set categories of such grain boundaries. 

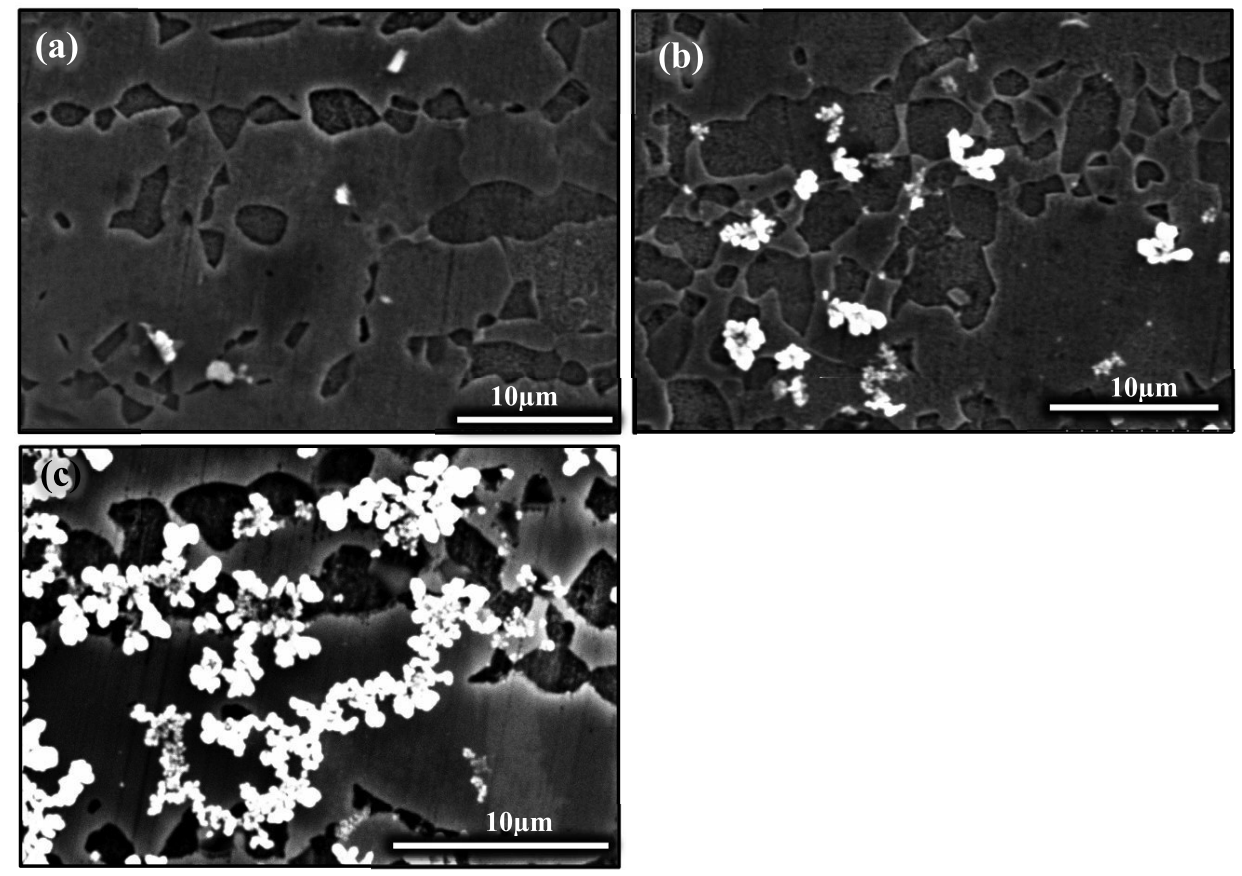

Fig. 8. SEM images of HMPT of the specimens tensile-loaded up to three levels of elastic stress at the strain rate of $\dot{\varepsilon}=1.38 \times 10^{-4} \mathrm{~s}^{-1}$. (a) $30 \%$, (b) $60 \%$, and (c) $90 \%$ of $0.2 \%$ proof stress

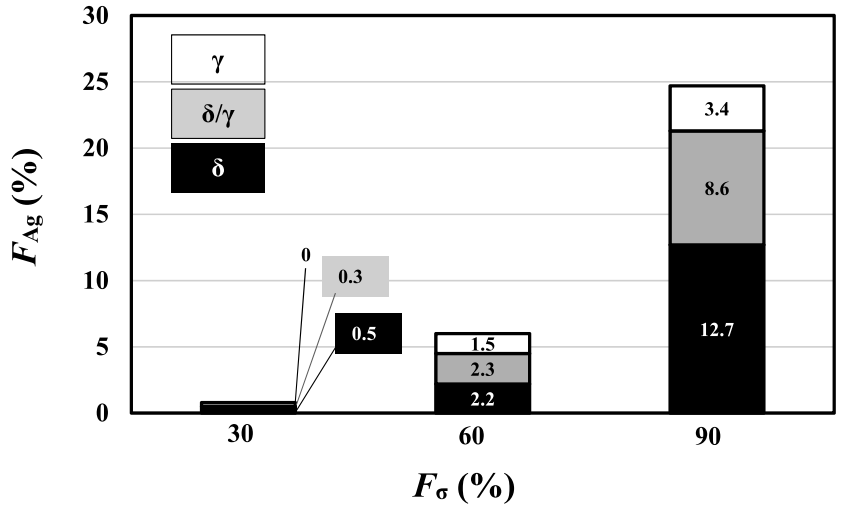

Fig. 9. Area fraction of the silver grains, $F_{\mathrm{Ag}}$, in the HMPT images of the test pieces as a function of percentage of elastic stress against $0.2 \%$ proof stress, $F_{\sigma}$, corresponding to the conditions in Fig. 8. Observed area: 1 255, 1082 and $637 \mu \mathrm{m}^{2}$ for $F_{\sigma}$ of 30,60 and $90 \%$, respectively.

\subsection{TDS}

Figure 11 shows hydrogen desorption spectra of the specimens $24 \mathrm{~h}$ hydrogen-charged with and without deformation. The spectrum of the specimen as-charged is also shown in the figure. By comparing the spectrum of the specimen held at ambient atmosphere after charging with that of the as-charged specimen, it is found that the peak position does not change although the amount of hydrogen slightly decreases. This means that some of the charged hydrogen simply diffused out while the rest remains in the same trapping site as in the as-charged specimen. In contrast, it is obvious that the deformation changes the peak position as well as markedly decreases the amount of hydrogen. Therefore, it is presumed that a certain amount of charged hydrogen migrates during the deformation into a new trapping site with lower binding energy. Although there has been no report on TDS result in DSS, phase boundary will be a stronger trapping site than those inside the ferrite

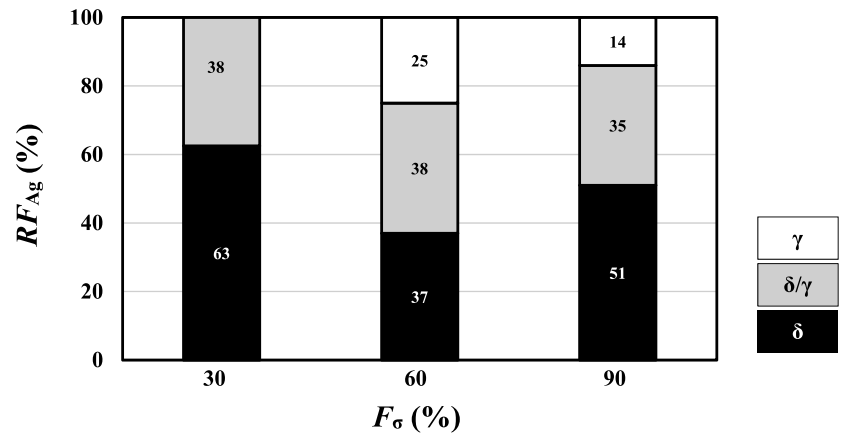

Fig. 10. Relative area fraction of the silver grains, $R F_{\mathrm{Ag}}$, in the HMPT images of the test pieces as a function of $F_{\sigma}$, corresponding to the conditions in Fig. 9.

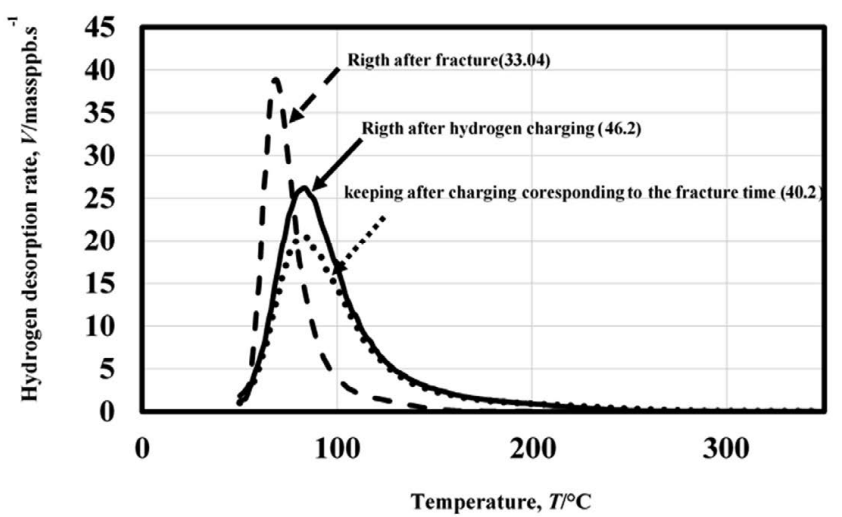

Fig. 11. Thermal desorption spectra of $24 \mathrm{~h}$ hydrogen-charged sample affected by the deformation at the strain rate of $1.38 \times 10^{-4} \mathrm{~s}^{-1}$ up to fracture and by keeping in the ambient air for the same time as the fracture time. Total amount of desorbed hydrogen is indicated in the parentheses in mass ppm.

phase such as the interstitial site (matrix), dislocation and ferrite/ferrite grain boundary according to the recent study ${ }^{34)}$ by the authors' group. Thus, it is presumed that the trapping 
site in the as-charged specimen is phase boundary and that the new trapping site in the deformed specimen is dislocations inside the ferrite phase, considering the too small trapping energy for the ferrite matrix that cannot be shown in the normal TDS, ${ }^{35)}$ far lower fraction of ferrite/ferrite grain boundary in DSS than in ferrite base iron and steels, and high dislocation density after deformation. The fact that the hydrogen amount of the deformed specimen is appreciably smaller than the sample simply held at the ambient air for the same duration is attributable to the hydrogen transportation with gliding dislocations. ${ }^{36)}$

\section{Discussion}

The results obtained can be summarized as follows: (i) delamination was confirmed in the fractured test piece; (ii) cracks initiated in ferrite grains, were arrested at austenite grains but finally propagated through austenite grains; (iii) dimpled area was observed in the fracture surface with some distance from the original surface as reported in the previous report by the authors, ${ }^{29)}$ (iv) the initiation of the delamination crack also occurred in ferrite grains; (v) HMPT showed that the hydrogen can migrate from the charged side to the other at room temperature for $24 \mathrm{~h}$, and the amount of hydrogen increased with the increase in elastic stress prior to the keeping; (vi) the sites where hydrogen desorped tend to be mostly ferrite phase, next phase boundary and least austenite phase, which was not significantly affected by the elastic stress; (vii) from TDS results, a certain amount of charged hydrogen was presumed to migrate during the deformation up to fracture into a new trapping site with lower binding energy. We will discuss these results with several papers previously reported.

On the delamination (result (i)), this was firstly observed by the authors but the mechanism for the initiation and propagation of the delamination remained unclear. However, in the present study, we have shown a clear evidence that the delamination crack initiates and propagates in ferrite phase. With respect to the crack initiation site, our result (ii) is in good agreement with those of Elhoud et al. ${ }^{37)}$ and partially with those of Luu et al. ${ }^{38)}$ The former reported that electrolytic hydrogen charging onto pre-strained super DSS caused reduction in elongation to failure depending on the amount of pre-strain, and that the crack initiated in ferrite phase, which was arrested by austenite phase. Luu et al. showed that ferrite phase plays a major role in the HE of DSS but with cleavage fracture associated with plastic deformation in the austenite phase in the fractured sample pre-charged with 5 times larger current density for 30 times longer period. On the other hand, Glowacka and Świątnicki ${ }^{39)}$ reported that the crack initiated in austenite and ferrite interphase boundary and in the stacking fault in austenite phase. However, they drew this conclusion from their TEM (transmission electron microscopy) observation where the thin foil specimen was charged with hydrogen. This charging condition is thought to change the hydrogen distribution from the situation in the bulk test piece. From these points, it can be concluded that the HE cracks initiate and initially propagate in ferrite phase when the charging condition is moderate.

Next, regarding the dimpled area remaining in the fracture surface of the charged sample (result (iii)), no other researcher pointed out this phenomenon. We presumed that the occurrence of the dimpled area might be caused either by the smaller concentration in the center of the test piece, or by strain rate increase that is brought about by the localized deformation once one of the microcracks grows to the major crack. From the HMPT result (v), hydrogen atoms can migrate from the charged side to the other, but the diffusion condition is somewhat different from that in the tensile test. In the HMPT, the sample was hydrogen-charged, emulsioncovered, tensile loaded, unloaded and then kept for $24 \mathrm{~h}$ at room temperature, while in the tensile test, the test piece was hydrogen-charged and then tensile-tested up to fracture, which took about $0.75 \mathrm{~h}$. The authors' group ${ }^{34)}$ made HMPT on the cross section of the sample hydrogen-charged and kept in the same condition as in the present paper but with no elastic stress loading, and found silver particles with area fraction of $1.7 \%$, which is about twice of the value of the present study of the sample loaded with $30 \%$ of the proof stress. Considering the distance from the charged surface, the loading with $30 \%$ of the proof stress is thought to have no effect. It is to be noted that the stress loading with $90 \%$ of the proof stress raise the amount of hydrogen by 30 times compared to that with $30 \%$ of the proof stress. This can compensate the difference in diffusion time for the tensile test and HMPT.

Also, hydrogen can move even during the charging for $24 \mathrm{~h}$. From these considerations, the amount of hydrogen was sufficient in the middle thickness region. Thus, it is deduced that the occurrence of the dimpled area is caused not by the smaller concentration in the center of the test piece, but by strain rate increase that is brought about by the localized deformation once one of the microcracks grows to the major crack.

With respect to the trapping site and diffusion path related to the results (vi), García ${ }^{40)}$ visualized the DSS surface opposite to the hydrogen-charged side by means of HMPT, and represented that the preferential hydrogen desorption site and diffusion path in the DSS is the interphase boundary between austenite and ferrite.

However, it is uncertain whether the hydrogen introduced at the charged side diffused to the other side only along the interphase boundary, since they did not show the microstructure of the specimen. According to the present study and other previous results, austenite grains are island-shaped (isolated) in ferrite matrix in thickness direction. Thus, hydrogen atoms at the charged side cannot reach the other side if the interphase boundary is the only diffusion path. To approve the mentioned opinion, the cross section of the hydrogen charged specimen was subjected to the HMPT by author's group. ${ }^{34)}$ Hydrogen was detected both in the ferrite matrix and phase boundary on the surface (charged side) and in the middle portion of thickness with different volume fraction. The results confirmed that some of the charged hydrogen atoms diffuse according to the hydrogen concentration gradient toward the other side, leaving the interphase boundary to the ferrite matrix. This phenomenon can be explained by assuming that not only the interphase boundary but also the ferrite matrix act as hydrogen diffusion path. Further discussion on the hydrogen diffusion path has been shown elsewhere. ${ }^{34)}$

Turnbull and Hutchings ${ }^{41)}$ also reported that interphase 
boundaries in DSS are effective trapping sites and can be responsible for the reduced diffusivity in electrochemically hydrogen-charged DSS specimens, based on hydrogen atom transport theory in a two-phase alloy. In contrast, Luu et $a l .{ }^{38)}$ visualised most of hydrogen in ferrite phase by means of HMPT. Furthermore, they claimed that hydrogen transportation in this steel is mainly lattice diffusion in ferrite and did not mention about the role of phase boundary in the diffusion path. Yalçì and Edmonds ${ }^{42)}$ revealed that austenite/ ferrite interphase boundary and austenite phase could act as a preferential hydrogen trapping site in DSS. Also, they reported the retarding effect of austenite/ferrite interphase boundary due to the trapping of hydrogen. All the previous authors drew their conclusion with one or a few images of HMPT or TARG (tritium autoradiography). Thus, there has not sufficient evidence on the trapping and diffusion of hydrogen during deformation. In contrast, in our present study we observed statistically meaningful area, classifying the sites to ferrite phase, ferrite/austenite phase boundary and austenite phase. Therefore, the observed fraction of hydrogen classified into three sites in the present study is deduced to be most reliable. From this result and theoretical approach by Turnbull and Hutchings, major diffusion path of hydrogen was concluded to be ferrite phase, and phase boundary was regarded as relatively strong trapping site.

Finally, on the result from TDS (vii), a certain amount of charged hydrogen was presumed to migrate during the deformation up to fracture into a new trapping site with lower binding energy. This apparently seems contradictory to the theory that hydrogen moves from less stable site to more stable site. Although further study is needed on this point, the most plausible candidate for the new trapping site is dislocation since it increases in number by plastic deformation.

\section{Conclusions}

Close observation on crack initiation site and propagation path, as well as delamination path in the electrolytically hydrogen-charged and tensile-deformed DSS, was carried out on the specimen in the course of the deformation as well as the fracture surface and the area close to the fracture point. In addition, the hydrogen behavior was correlated to the cracking process by means of HMPT and TDS. The following conclusions were obtained:

(1) Microcracks initiated in the ferrite phase at a strain of $12 \%$ perpendicular to the tensile direction and the number of them increased with increasing strain up to $20 \%$.

(2) Austenite phase acted as an obstacle against crack propagation at all deformation stages.

(3) Delamination crack initiated and propagated in ferrite phase, while the step cracks were deduced to be formed by the ductile deformation in the core portion related to the dimpled fracture process that separate the pre-existing surface cracks both in tensile and thickness directions.

(4) HMPT made at the side opposite to the charging side revealed that hydrogen atoms migrate mainly in ferrite phase over the distance of the sample thickness. The HMPT also revealed a marked effect of elastic stress on the acceleration of hydrogen diffusion.

(5) Considering this long diffusion distance of hydro- gen, dimpled area observed around the center of the fracture surface was attributable to the sharp increase in the strain rate because of the localized deformation arising from the major crack propagation.

(6) TDS results in the as charged and as deformed samples confirmed a certain amount of charged hydrogen migrates during the deformation into the new trapping site with lower binding energy such as dislocation inside the ferrite phase, while the rest to diffuse out, both presumably by the mechanism of the hydrogen transportation with gliding dislocations.

\section{REFERENCES}

1) M. Knyazeva and M. Pohl: Metallogr. Microstruct. Anal., 2 (2013), 113.

2) R. B. Hutchings, A. Turnbull and A. T. May: Scr. Metall. Mater., 25 (1991), 2657.

3) G. Chail and P. Kangas: Procedia Struct. Integr., 2 (2016), 1755.

4) K. H. Lo, C. H. Shek and J. K. L. Lai: Mater. Sci. Eng., R65 (2009), 39.

5) W. Y. Wei, C. H. Tzeng and J. K. Wu: J. Mater. Sci. Lett., 9 (1990), 1357.

6) H. L. Eschbach, F. Gross and S. Schulien: Vacuum, 13 (1963), 543.

7) S. L. Chou and W. T. Tsai: Mater. Sci. Eng. A, 270 (1999), 219.

8) T. Cassagne and F. Busschaert: Corrosion 2005, NACE International, Houston, (2005), Paper No. 05098.

9) Y. Mukai, M. Murata and J. Wang: Q. J. Jpn. Weld. Soc., 9 (1991), 245 (in Japanese).

10) M. Murata, J. Wang and Y. Mukai: Zairyo-to-Kankyo, 40 (1991), 461 (in Japanese).

11) H. Masuda and S. Matsuoka: Zairyo-to-Kankyo, 49 (2000), 379 (in Japanese).

12) K. Kurose, H. Cho, T. Ogawa and M. Takemoto: J. Soc. Mater. Sci. Jpn., 57 (2008), 1084 (in Japanese).

13) M. Nagumo: Tetsu-to-Hagané, 90 (2004), 766 (in Japanese).

14) M. Nagumo: ISIJ Int., 52 (2012), 168.

15) T. Nakayama and H. Tanaka: Tetsu-to-Hagané, 100 (2014), 1089 (in Japanese).

16) A. Barnoush and H. Vehoff: Acta Mater., 58 (2010), 5274

17) T. Zakroczymski, A. Glowacka and W. Swiatnicki: Corros. Sci., 47 (2005), 1403.

18) M. Nagumo: ISIJ Int., 41 (2001), 590.

19) M. Nagumo, M. Nakamura and K. Takai: Metall. Mater. Trans. A, 32 (2001), 339

20) V. Olden, C. Thaulow and R. Johnsen: Mater. Des., 29 (2008), 1934.

21) R. Silverstein and D. Eliezer: J. Alloy. Compd., 644 (2015), 280.

22) R. Silverstein, O. Sobol, T. Boellinghaus, W. Unger and D. Eliezer: J. Alloy. Compd., 695 (2017), 2689.

23) Y. Yagodzinskyy, O. Todoshchenko, S. Papula and H. Hänninen: Steel Res. Int., 82 (2011), 20.

24) I. Maroef, D. L. Olson, M. Eberhart and G. R. Edwards: Int. Mater. Rev., 47 (2002), 191.

25) K. Ebihara and H. Kaburaki: ISIJ Int., 52 (2012), 181.

26) K. Ichitani, M. Kanno and S. Kuramoto: ISIJ Int., 43 (2003), 496.

27) I. M. Robertson, P. Sofronis, A. Nagao, M. L. Martin, S. Wang, D. W. Gross and K. E. Nygren: Metall. Mater. Trans. B, 46 (2015), 1085.

28) E. Owczarek and T. Zakroczymski: Ochrona Przed Korozja, XLII (1999), 467

29) A. Yousefi and G. Itoh: ISIJ Int., 58 (2018), 561.

30) T. Izumi and G. Itoh: Mater. Trans., 52 (2011), 130.

31) H. Saitoh, Y. Iijima and K. Hirano: J. Jpn. Inst. Light Met., 36 (1986), 286 (in Japanese).

32) N. Kheradmand, R. Johnsen, J. S. Olsen and A. Barnoush: Int. J. Hydrog. Energy, 41 (2016), 704.

33) S. Kuramoto and M. Kanno: Zairyo-to-Kankyo, 49 (2000), 265 (in Japanese).

34) Z. Ghorani, A. Yousefi and G. Itoh: ISIJ Int., 59 (2019), No. 10, 1901.

35) K. Takai: Zairyo-to-Kankyo, 60 (2011), 230 (in Japanese).

36) J. K. Tien, A. W. Thompson, I. M. Bernstein and R. J. Richards: Metall. Trans. A, 7 (1976), 821.

37) A. M. Elhoud, N. C. Renton and W. F. Deans: Int. J. Hydrog. Energy, 35 (2010), 6455.

38) W. C. Luu, P. W. Liu and J. K. Wu: Corros. Sci., 44 (2002), 1783

39) A. Glowacka and W. A. Świątnicki: J. Alloy. Compd., 356-357 (2003), 701.

40) J. Ovejero-García: J. Mater. Sci., 20 (1985), 2623.

41) A. Turnbull and R. B. Hutchings: Mater. Sci. Eng., A177 (1994), 161.

42) H. K. Yalci and D. V. Edmonds: Mater. Charact., 34 (1995), 97. 